\title{
JARDIM DO MAC - CIDADE UNIVERSITÁRIA
}

\author{
PAULO RENATO MESQUITA PELLEGRINO \\ e VLADIMIR BARTALINI
}

\section{RESUMO}

O tratamento paisagístico do espaço em frente ao Museu de Arte Contemporânea na Cidade Universitária teve por objetivos:

1. ambientar as esculturas existentes;

2. prover espaço para eventos artísticos ao ar livre;

3. atender ao fluxo de pedestres entre o centro de convivência, situado ao lado do Museu, e a praça do Relógio, em um outro lado.

O projeto baseou-se na modulação da arquitetura do Museu e em suas diagonais, projetando sobre o chão uma grelha geométrica. Os polígonos assim formados foram ora preenchidos com arbustos de pequeno e médio portes, ora com material pisoteável, formando um jardim em mosaico.

\section{ABSTRACT}

Landscape Design in front of the Museum of Contemporary Art (USP Cidade Universitária, São Paulo)three goals had to be reached in this project:

1. to create a setting for the sculptures already placed in the open space;

2. to provide area for artistic events;

3. to allow the pedestrian crossing between the students living center beside the Museum and a big square at its other side.

The landscape design was based on the Museum Architecture's modulation and on its diagonals creating a geometric grid on the ground. The voids were fulfilled sometimes with plants, sometimes with paving materials, resulting a mosaic like garden. 
Pela passagem do $60^{\circ}$ aniversário da fundação da Universidade de São Paulo, o Museu de Arte Contemporânea da USP organizou um evento no espaço livre em frente ao edifício do museu, na Cidade Universitária, que contou com a participação de 60 artistas convidados.

Tratava-se da exposição de 60 trabalhos especialmente criados para a ocasião, em panos fixados em mastros, como bandeiras.

O evento foi programado para durar apenas um fim de semana, durante o qual a exposição temporária das bandeiras dividiria o espaço com as esculturas, estas expostas em caráter permanente ao ar livre, na frente do Museu.

À equipe de paisagismo da FAUUSP competiu organizar o espaço da amostra, com os seguintes requisitos:

- Compatibilizar o caráter provisório da amostra com a exposição permanente das esculturas.

- Extrapolar a duração e a natureza da exposição, projetando um espaço adaptável a usos distintos e a diversos eventos.

- Integrar a área livre do Museu ao espaço do campus, tanto como local de estar, de fruição, como de circulação de pedestres.

- Possibilitar a rápida execução do projeto e sua "resposta" a curto prazo, dado o pouco tempo disponível entre a solicitação do projeto e a realização do evento.

O projeto baseou-se formalmente no rebatimento da modulação do edifício do museu sobre o chão livre frontal. Formaram-se então grandes quadros retangulares, que foram em seguida submodulados numa grade regular.

A passagem de pedestres entre o Centro de Convivência e a praça do Relógio, que já ocorria espontaneamente cruzando o espaço aberto, foi contemplada bem com a presença das esculturas ali existentes.

Assim, recortaram-se os submódulos em seus lados e diagonais de modo a se configurar um espaço não só de passagem, mas também para apreciação das obras expostas e para a realização de futuros eventos.

Nos vértices dos submódulos foram embutidos dispositivos para receber os mastros, distribuídos irregularmente ao longo da passarela.

Os grandes módulos foram preenchidos com espécies herbáceas e arbustivas variadas, escolhidas por critérios baseados no cromatismo, na textura e no porte da vegetação, 
criando um grande painel mosaicado. Painel em parte formado por um jardim vegetal, um ambiente para as esculturas, onde as obras de arte, fixas e conclusivas, compõem um contraponto com o espaço menos controlável e em permanente mutação dos seres vivos; e em parte formado pela matéria inerte do piso, plano de passeio e de passagem, como um fundo contínuo e homogêneo a acolher a intermitência e a imprevisibilidade de propósitos e representações.
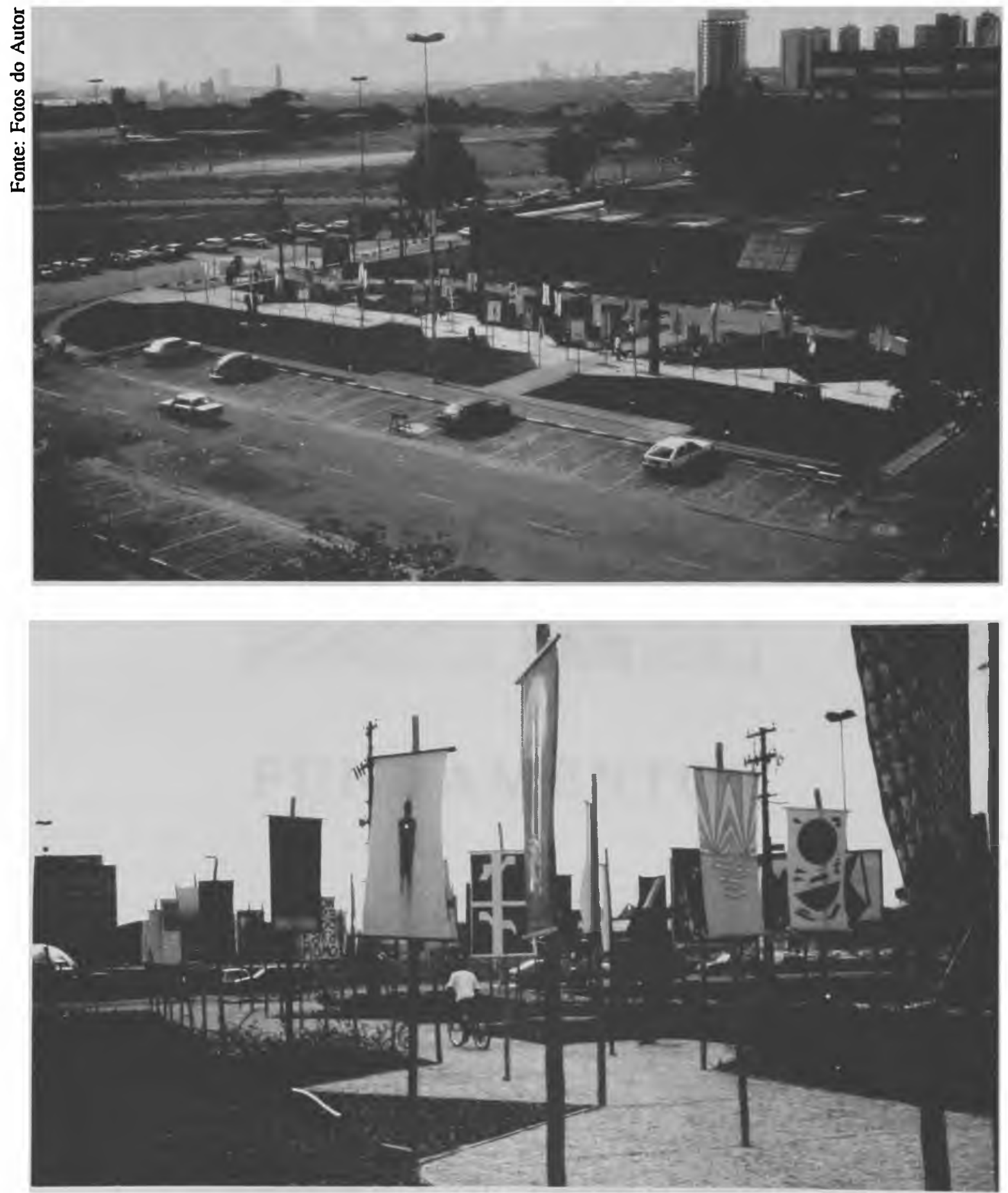

Vista Geral do Jardim do Mac-USP

Paisagem Ambiente Ensaios São Paulo n. 7 p. 9 - 12 jun. 1995 


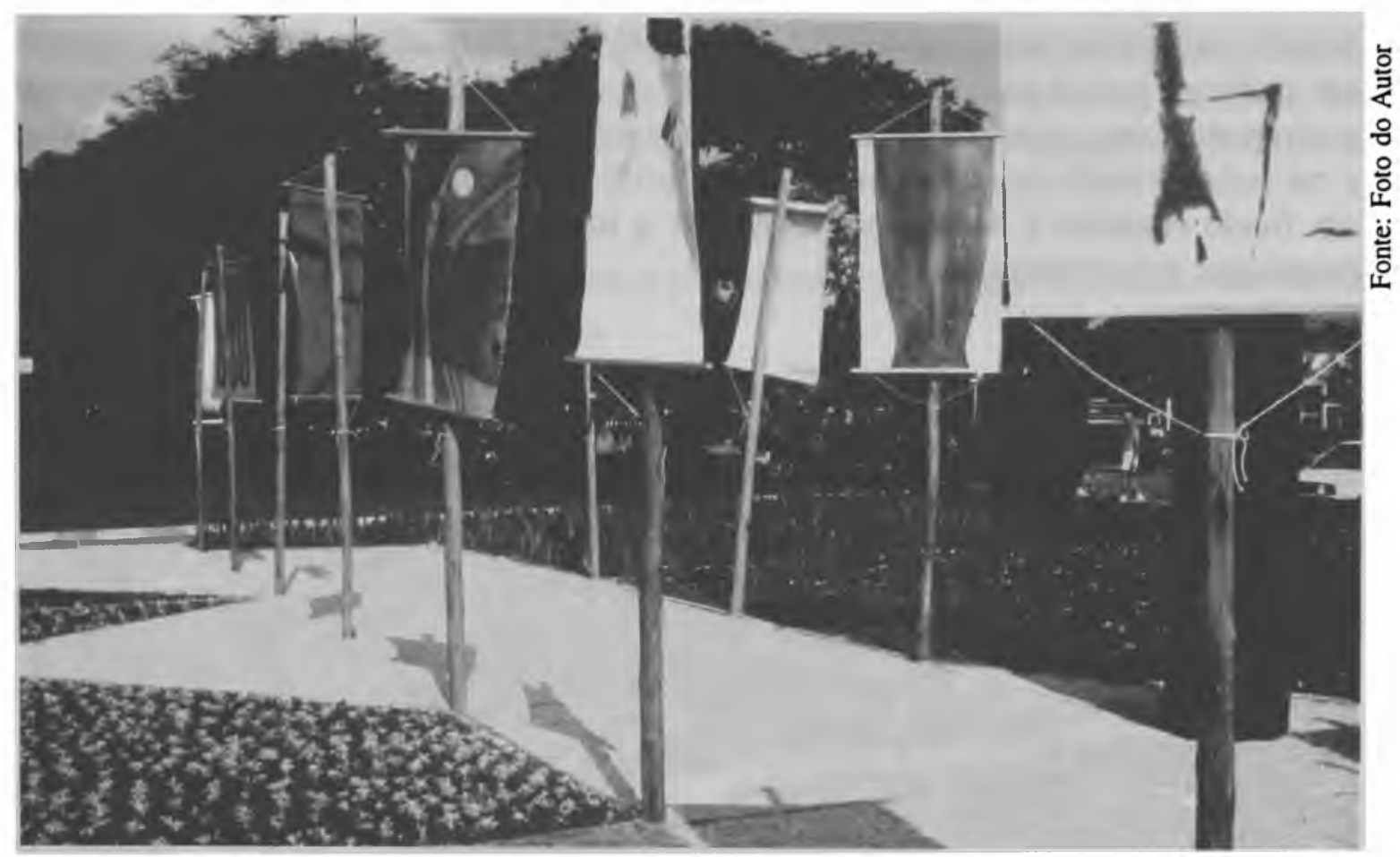

Detalhe da Instalação 